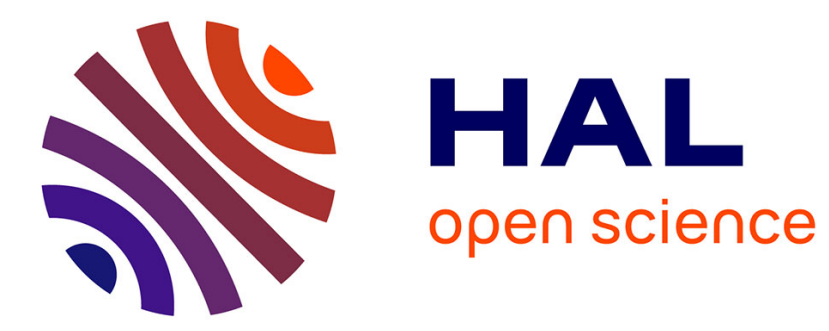

\title{
Introduction of variability into pantograph-catenary dynamic simulations
}

Olivier Vo Van, Jean-Pierre Massat, Christophe Laurent, Etienne Balmès

\section{To cite this version:}

Olivier Vo Van, Jean-Pierre Massat, Christophe Laurent, Etienne Balmès. Introduction of variability into pantograph-catenary dynamic simulations. Vehicle System Dynamics, 2014, 52 (10), pp.12541269. 10.1080/00423114.2014.922199 . hal-01102777

\section{HAL Id: hal-01102777 https://hal.science/hal-01102777}

Submitted on 13 Jan 2015

HAL is a multi-disciplinary open access archive for the deposit and dissemination of scientific research documents, whether they are published or not. The documents may come from teaching and research institutions in France or abroad, or from public or private research centers.
L'archive ouverte pluridisciplinaire HAL, est destinée au dépôt et à la diffusion de documents scientifiques de niveau recherche, publiés ou non, émanant des établissements d'enseignement et de recherche français ou étrangers, des laboratoires publics ou privés. 


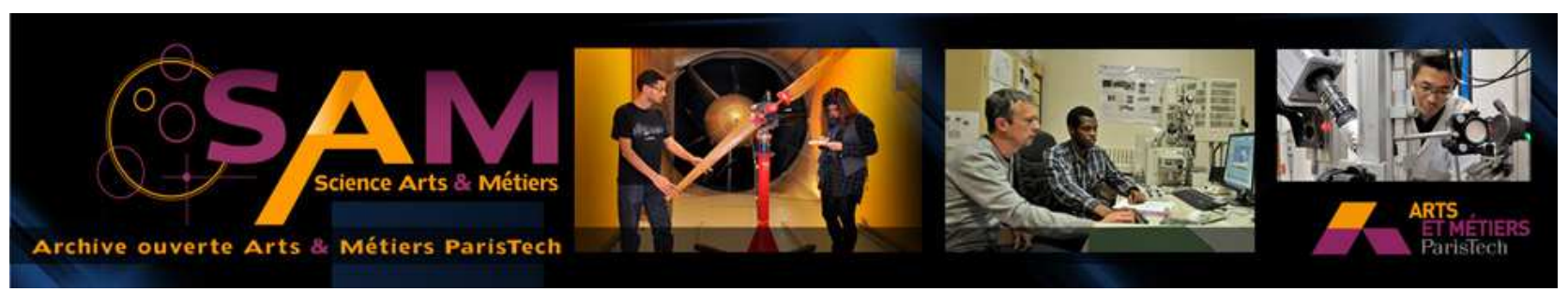

Science Arts \& Métiers (SAM)

is an open access repository that collects the work of Arts et Métiers ParisTech researchers and makes it freely available over the web where possible.

This is an author-deposited version published in: http://sam.ensam.eu

Handle ID: .http://hdl.handle.net/10985/9224

\section{To cite this version :}

Olivier VO VAN, Jean-Pierre MASSAT, Christophe LAURENT, Etienne BALMES - Introduction of variability into pantograph-catenary dynamic simulations - Vehicle System Dynamics - Vol. 52, $\mathrm{n}^{\circ} 10$, p.1254-1269- 2014 


\title{
Introduction of variability into pantograph-catenary dynamic
}

\section{simulations}

\author{
Olivier Vo Van ${ }^{* \dagger \dagger}$, Jean-Pierre Massat ${ }^{\star}$, Christophe Laurent ${ }^{\pi}$ and \\ Etienne Balmès ${ }^{\dagger}$
}

\author{
${ }^{\dagger}$ PIMM, Arts \& Metiers ParisTech, Paris, France; ${ }^{\pi}$ Vibrateam (Vibratec Group), Lyon, \\ France; ${ }^{*}$ SNCF research department, Paris, France
}

\begin{abstract}
Currently, pantograph-catenary dynamic simulations are mainly based on deterministic approaches. However, the contact force between catenary and pantograph depends on many key parameters that are not always quantified precisely and can vary in time and space. To get a better chance of addressing extreme or combined critical conditions, methodologies to consider variability are thus necessary. Aerodynamic forces and geometrical irregularities of catenaries are thought to be significant sources of variability in measurement and this paper proposes methods to take them into account. Results are compared with measurements to correlate the effect of the considered parameters with experimentally observed variability. Finally, a virtual certification example is shown, with a study of the influence of speed on the impact of variability.
\end{abstract}

Keywords: Pantograph-catenary interaction; Variability; Dynamic simulation

\section{Introduction}

Today, the minimization of rolling stock impact on infrastructure is a leading objective in the railway sector. In this context, requirements on current collection quality given by the Technical Specifications for Interoperability (TSI) are likely to become much restrictive in the next few years. However, performance of existing pantographs has almost reached their physical limits, especially in the case of train sets with multiple pantographs.

Since inline test give limited knowledge of the system response and are limited due to conflicts with commercial traffic, virtual tools [1] are certain to represent a growing part of the effort on optimisation and sensitivity studies. Examples of optimisation studies are [2], which aims to limit breakages and to improve current collection quality under knuckle junctions, or [3] in which the parameters studied are pantograph suspension characteristics. For sensitivity analyses, Ref. [4] analyses span length, static uplift force and pantograph system parameters, and Ref. [5] analyses catenary geometry through installation error indices.

Based on SDTools libraries, SNCF has developed an efficient and powerful finite element library for the simulation of pantograph/catenary interaction named OSCAR [6]. This software is certified against EN50318 and validated against measurements. It is routinely used for design studies. Although OSCAR has been developed on deterministic approach, it is quite clear that a basic statistical strategy

\footnotetext{
* Corresponding author.Email: olivier.vo_van@sncf.fr
} 
would give a higher confidence in results and be useful for industrial use. This paper presents the first developments of this new methodology, introducing three kinds of irregularities, namely catenary geometry irregularity, catenary wear and transient aerodynamic forces.

The case study is based on the French pantograph CX made by Faiveley running under the east high-speed line between Paris and Strasbourg allowing a maximum speed of $320 \mathrm{~km} / \mathrm{h}$. Some homologation measurements done by SNCF's testing agency (Agence d'Essais Ferroviaires) and others resulting from maintenance measurement campaigns are used to establish the source of variable parameters impacting performance.

Geometrical irregularities of catenaries, contact wire wear and aerodynamic forces are first introduced as physical sources of variability and characterized by measurements. Section 3 then proposes methodologies to take these sources into account. Results of simulations are then compared to each other and with measurements to identify the main physical phenomena. In section 4 , the proper selection of observation criteria is shown to be a critical aspect of the proposed analysis. Finally, section 5 details an example typical for virtual certification highlighting the importance of vehicle speed.

\section{Sources of variability analysis}

Three physical perturbations and associated measurements are studied in the following section:

- geometric irregularities, which correspond to the actual height of the contact wire, given in $[\mathrm{cm}]$,

- contact wire wear which is defined by the contact wire section, given in $\left[\mathrm{mm}^{2}\right]$,

- aerodynamic irregularities, defined as a perturbation around the mean aerodynamic applied force, given in [N].

\subsection{Geometric irregularity}

Geometric irregularity characterizes differences between nominal and real geometry of the catenary particularly at mast and dropper positions. The nominal geometry is defined by perfectly regular sag of $1 / 2000$ and a fixed height identical for every mast. This study focuses on parameters like dropper length and mast height, which affect the contact wire static height. Figure 1 shows that the measurement is much less regular than the theoretical design. The spatial and spectral representations are given for measurements in solid line and for the nominal height of the catenary in dashed line.

Measurements are low-pass filtered using a 20-points moving average method. This corresponds to a filter at $0.25 \mathrm{~m}^{-1}$ or $4 \mathrm{~m}$, which is smaller than the smallest interdropper distance. Higher frequency irregularities are not taken into account since they cannot be caused by geometric irregularities. 
(a) Contact Wire Height

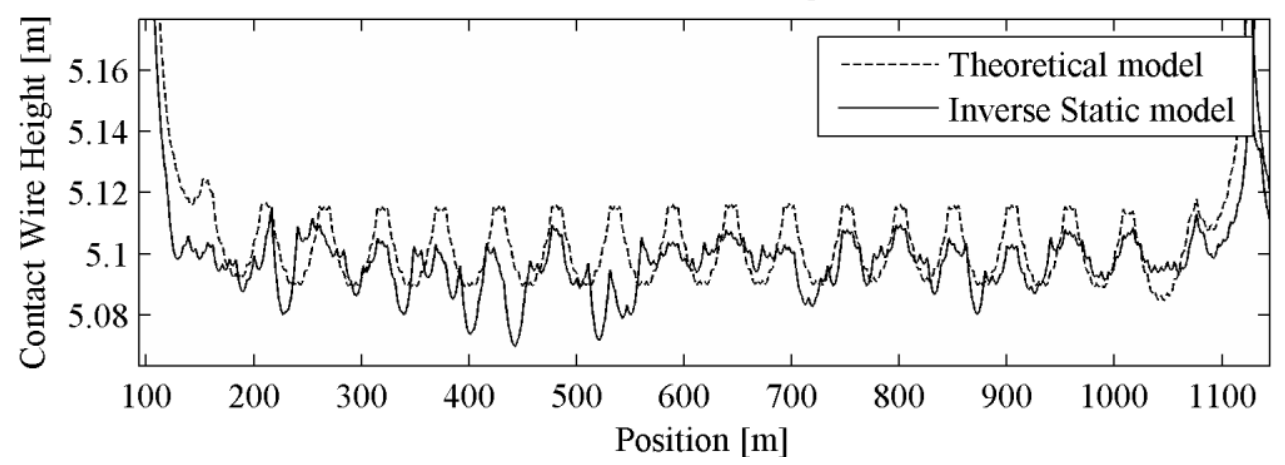

(b)

Contact Wire Height Spectrum

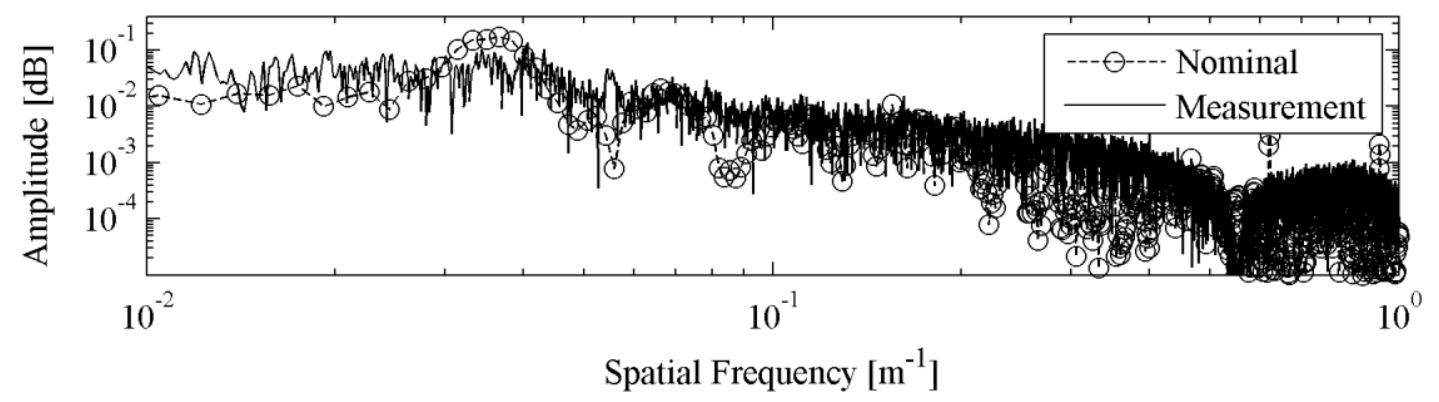

Figure 1. Filtered measurements (solid line) and nominal (dashed line) contact wire height (a) and spatial-spectrum of contact wire height (b)

\subsection{Contact wire wear}

Wear can slightly modify dynamic behaviour of the catenary since it acts on local stiffness and on contact wire height. It is characterized by a decrease of section area $A\left[\mathrm{~mm}^{2}\right]$ and an increase of contact wire height $[\mathrm{mm}]$.

In-line measurements are used to determine a mean wear over the contact wire. These global values permit to define coefficients of a wear law defined experimentally [7] as:

$$
A=k_{1} \times\left(1+i / i_{0}\right)^{-\alpha} \times\left(F_{c} / F_{0}\right)^{\beta} \times V / V_{0} \times F_{c} / H \times k_{2} \times R\left(F_{c}\right) \times i^{2} /(H \cdot V)
$$

with

$$
R\left(F_{c}\right)=k_{r} /\left(F_{c}{ }^{1 / 2}\right)
$$

where $A$ is the surface removed by one pantograph passage, $F_{c}$ the load, $i$ the current and $V$ the train speed. $V_{0}, i_{0}$ and $F_{0}$ are used for normalization and taken equal to nominal values, i.e. $V_{0}=3 \mathrm{~m} / \mathrm{s}, i_{0}=426 \mathrm{~A}, F_{0}=190 \mathrm{~N}$. $k_{1}, k_{2}, \alpha$ and $\beta$ are the adimensional parameters defined to fit with measurements. $H$ is the hardness of the softer of the two materials, $H=110 \mathrm{HR}$. Finally, $k_{r}$ is a coefficient used to interpolate the relationship between $R$ and $F_{c}, k_{r}=4.9710^{-2} \Omega . \mathrm{N}^{1 / 2}$. 


\subsection{Aerodynamic irregularities}

The aerodynamic irregularity is defined as a time varying vertical force fluctuating around the mean aerodynamic force applied on the pantograph. This variation is due to changes in different parameters such as train speed or wind speed and direction. Available measurements are used to compute the mean aerodynamic force. They are filtered at $1 \mathrm{~Hz}$ and give a reasonable indication of the variation range for the aerodynamic force. For the considered case at $320 \mathrm{~km} / \mathrm{h}$ shown on Figure 2, one has a mean of $96 \mathrm{~N}$ and a range of variation between $83 \mathrm{~N}$ and $109 \mathrm{~N}$ with a $95 \%$ confidence interval. The use of the same data for irregularity studies will be discussed in the next section.

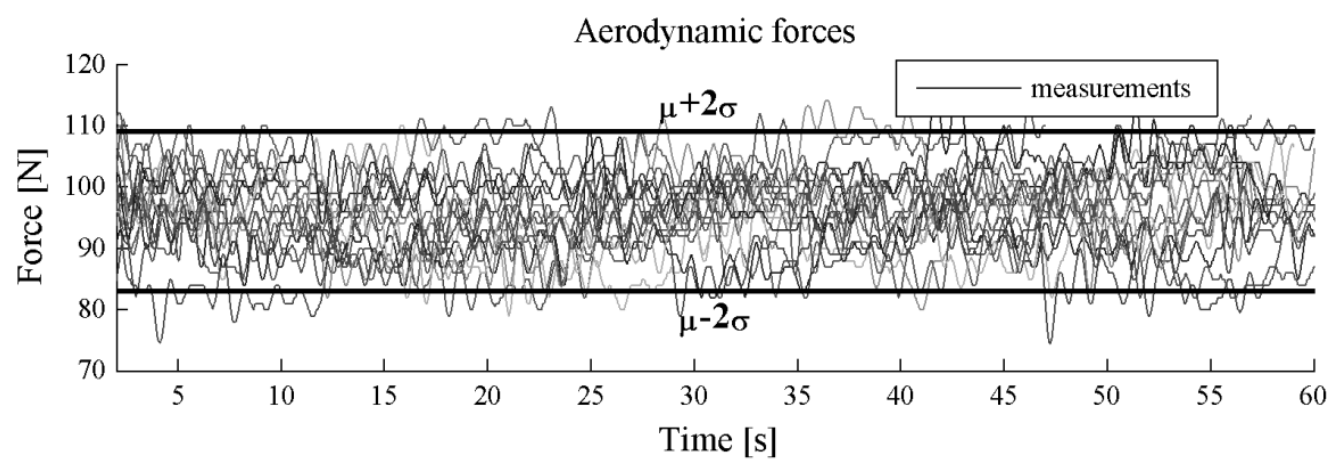

Figure 2. Measured aerodynamic forces (normal lines) and 95\% probability interval (bold lines)

\section{Integrating uncertainty in simulation tools}

The method to account for each uncertainty depends on how each parameter influences the dynamic behaviour and will be detailed in subsections. All considered cases however share a random signal generation process. The classical method used here is to affect a random phase $\varphi_{n}$, in the $[-\pi, \pi]$ interval, to a spectrum of known amplitude $A_{n}$ and to compute the response by inverse Fourier transform.

$$
z(k \Delta x)=\sum_{n=1}^{N}\left|A_{n}\right| e^{\left(\frac{j 2 \pi k n}{N}+\varphi_{n}\right)}
$$

where zero mean is achieved by setting $A_{0}=0$ and the spectrum is constrained to be symmetric (that is $A_{N-n}=A_{n}$ and $\varphi_{\mathrm{N}-\mathrm{n}}=-\varphi_{\mathrm{n}}$ ) to obtain a real realization by inverse Fourier transform.

\subsection{Geometric irregularities}

Between droppers and spans the geometry is only linked to tension, beam section and gravity which are well known. The proposed strategy is thus to use random values for contact wire height at dropper and span locations. Wear induces height modifications whose dynamic impact is very low for long wavelengths. One can thus neglect geometry modifications induced by wear. 
One thus first generates a random signal with equation (3.1) using the amplitude spectrum shown in dashed line in Figure 1(b), which corresponds to the filtered measurement. Given this signal, an inverse static computation is performed by modifying dropper length of the nominal catenary in order to converge to the target position of contact wire at dropper and span locations. The resulting catenary mesh is then used in dynamic simulations, taking into account geometric irregularities. Figure 3 shows an example of sag obtained from the nominal catenary model and the target height after a static computation. Figure $3 \mathrm{~b}$ illustrates the difference in sag and demonstrates that the target geometry is reached with a gap of less than $0.1 \mathrm{~mm}$ along the contact wire. The highest variations come from the approximation of the masts height, which is negligible.
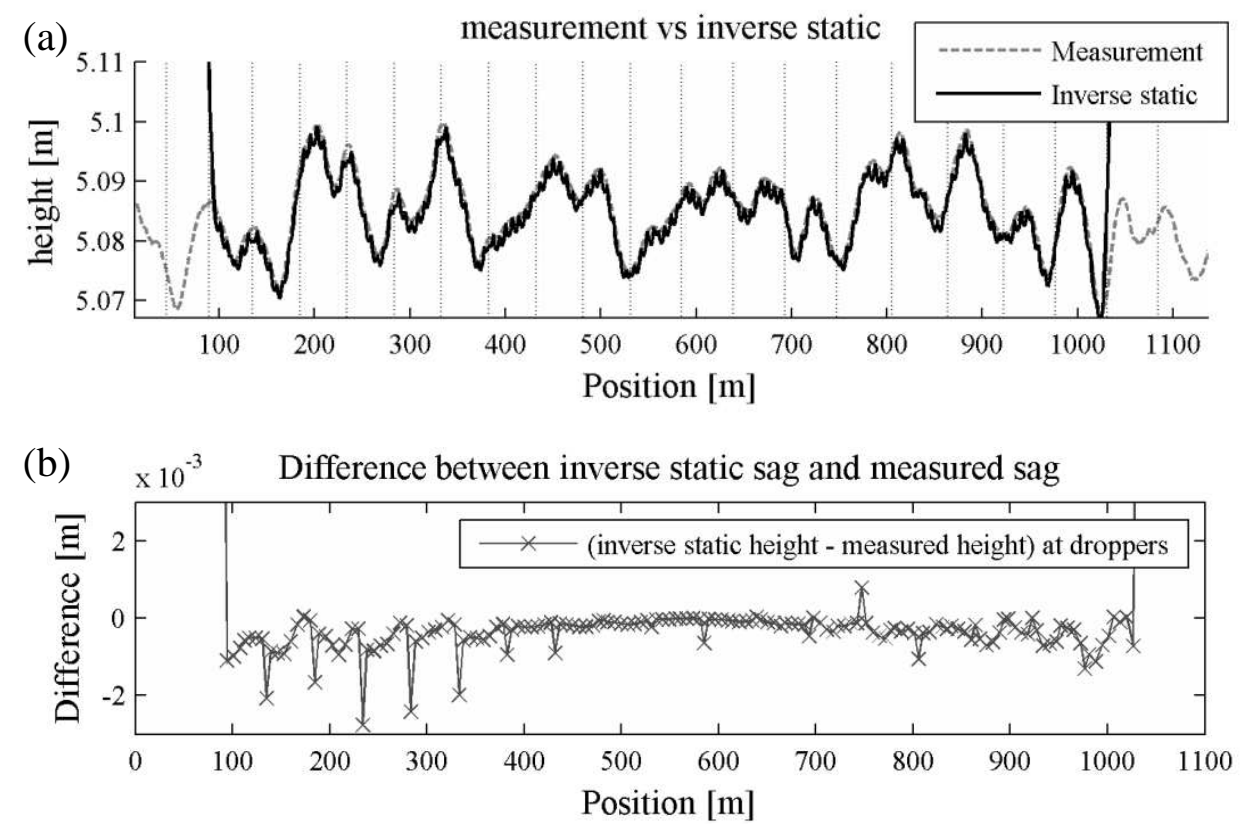

Figure 3. Comparison between contact wire height measured and computed by inverse static method: superposed heights (a) and differences of heights under droppers (b)

\subsection{Contact wire wear}

The spatial distribution of wear is not really random. Contact force is indeed usually higher in the same area of the contact wire. One thus prefers to generate a wear profile by using equation (2.1). One applies the contact force computed with the nominal geometry as $F_{c}$. The wear profile $A(x)$, obtained for one cycle, is then multiplied by a target number of cycles before renewing the contact force computation. The full lifespan of the contact wire is thus separated into $n$ linearly spaced simulations, $n$ representing the number of cycles varying between 0 and $10^{8}$.

As shown in Figure 4, wear induces a perturbation $d z$ to the vertical position of the contact point. In the time integration, solved with Newmark implicit method, one thus considers

$$
\mathrm{K} \cdot \mathrm{q}+\mathrm{C} \cdot \dot{\mathrm{q}}+\mathrm{M} \cdot \ddot{\mathrm{q}}=\mathrm{k}_{\mathrm{c}}\left(\mathrm{z}_{\text {cat }}+\mathrm{dz}-\mathrm{z}_{\text {panto }}\right)
$$

where $K$ is the stiffness matrix, $C$ the damping matrix, $M$ is the mass matrix, $z_{c a t}$, height 
of the contact wire corrected by the section change $d z$ and $z_{\text {panto }}$, height of the pantograph. $q$ is the displacement vector and $k_{c}$ the contact stiffness.

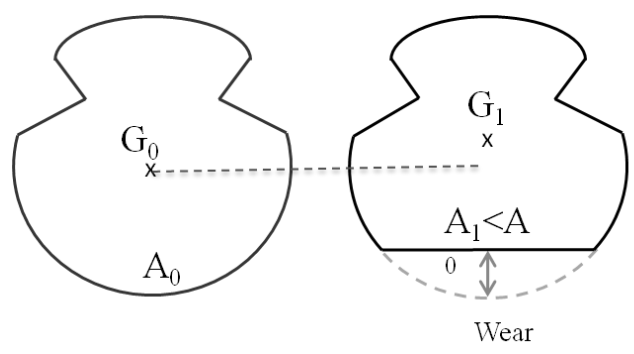

Figure 4. Contact wire section of a new wire (a) and a worn wire (b), $A$ being the area and $G$ the centre of gravity

The second effect is a section reduction of the contact wire which leads to a decrease of the local stiffness. As OSCAR uses FEM, stiffness variations cannot have higher frequency than the one induced by the element size. A constant stiffness is applied for each beam element of the contact wire, by averaging the random section wear signal over the element length. Both phenomena are taken into account at the same time in this study, which does not aim to analyse their impact separately.

\subsection{Aerodynamic irregularities}

As seen previously, measured aerodynamic forces are filtered at very low frequency. While defining a probability distribution for the aerodynamic force would be a classical approach, it does not contain any spectral information so that a different approach was preferred here. As shown in Figure 5, one defines a design force spectrum by extending the measurements to higher frequencies and uses this spectrum to generate a vertical load on the upper mass of the pantograph model that is random in time. The extension was done by roughly taking the mean value of the spectrum amplitude computed at $1 \mathrm{~Hz}$ as fixed amplitude between $1 \mathrm{~Hz}$ and $100 \mathrm{~Hz}$. The frequency under $1 \mathrm{~Hz}$ corresponds to a spatial frequency under $0.012 \mathrm{~m}^{-1}$ for a nominal speed of $83 \mathrm{~m} / \mathrm{s}$, which is under the span frequency, equal to $0.0185 \mathrm{~m}^{-1}(=1 / 54 \mathrm{~m})$. The value $100 \mathrm{~Hz}$ has been taken arbitrary.

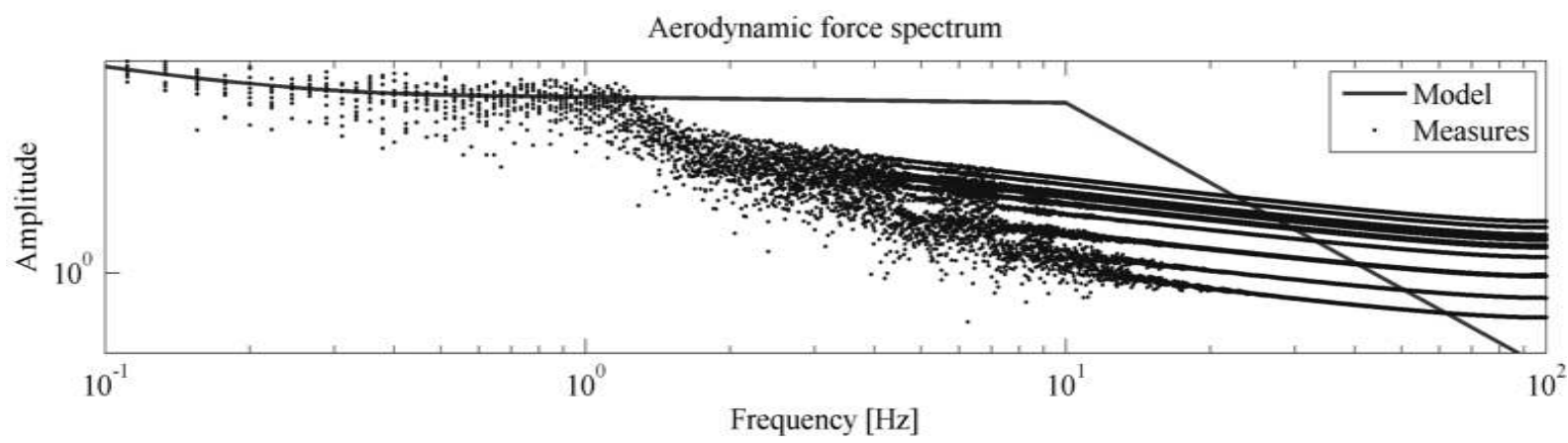

Figure 5. Aerodynamic force spectrum measured (dotted lines) and spectrum shape defined (solid line)

\section{Contact force analysis}

Directly comparison of contact forces in the time domain does not give a clear 
understanding of the impact of irregularities in particular due to the presence of phase differences with the measurements. To address this issue different comparison tools have been considered. Of the four detailed here, two are used to compare signals together, and two are used to compare signals to measurements.

\subsection{Criteria selection}

\section{Statistical values}

The main goal of pantograph-catenary simulation is to evaluate the current collection quality. The usual approach is to divide the contact-force standard deviation $\sigma$ by mean contact force, which has to be as low as possible and under 0.3 to meet standards. This is a statistical criterion which, assuming the load to follow a normal distribution, corresponds to a probability to lose contact of less than $1 \%$. This criterion is called coefficient of variation in statistics. For $n$ simulations, the first statistical moments can be considered as discrete variables of $i, i \in[1, n]$ on which standard deviation can be computed:

- $S_{1}=\sigma\left(F_{m, i}\right)$, with $F_{m, i}$ the mean contact force of the $i^{\text {th }}$ simulation,

- $S_{2}=\sigma\left(\sigma\left(F_{c, i}\right)\right)$, with $F_{c, i}$ the time signal of contact force of the $i^{\text {th }}$ simulation,

- $S_{3}=\sigma\left(\sigma\left(F_{c, i}\right) / F_{m, i}\right)$,

- $\operatorname{Min}_{3}=\operatorname{Min}\left(\sigma\left(F_{c, i}\right) / F_{m, i}\right)$,

- $\operatorname{Max}_{3}=\operatorname{Max}\left(\sigma\left(F_{c, i}\right) / F_{m, i}\right)$,

- $M_{3}=E\left(\sigma\left(F_{c, i}\right) / F_{m, i}\right)$,

- $M_{\text {nom }}=\sigma\left(F_{c, \text { nominal }}\right) / F_{m}$, nominal, with $F_{c \text {, nominal }}$ the time signal of contact force computed with the nominal speed and nominal contact force with the nominal model as defined in section 2.1 , and $F_{m \text {, nominal }}$ it's mean,

where $\sigma$ and $E$ denote the standard deviation and expectation operators computed over the $n$ simulations. S3 and M3 are the main criteria to define

\section{Spectrum of differences}

In order to compare simulations together more precisely than using a simple scalar criterion, the computation of the difference between two contact force spectra gives information about which frequencies are more affected by modifications. All simulations are compared with the nominal model. For each type of irregularity, results are averaged over a hundred simulations.

\section{Frequency band analysis}

Frequency Band Analysis (FBA), see more details in [8], is a comparison tool used to get a sharper discrimination of unsynchronized signals than a simple comparison of Power Spectral Density (PSD) without observing shift of frequency but only mean amplitude in frequency bands. FBA gives a graphical representation of variance against frequency. Defining a range of variation over a set of simulations gives information about the amplitude of variation of energy in a frequency band, which can easily be 
compared with measurements. In our case, frequency bands will be centred on the harmonics of median span frequency, which appeared to be the main contributors in the PSD.

Frequency coherence function:

The aim of the coherence function [8],

$$
\gamma_{x, y}^{2}\left(f_{k}\right)=\frac{\left|S_{y x}\left(f_{k}\right)\right|^{2}}{S_{x x}\left(f_{k}\right) \cdot S_{y y}\left(f_{k}\right)}
$$

is to assess and quantify if a linear relationship exists between two sets of frequency spectrums. As the numerator is the magnitude squared of a cross power spectrum and the denominator a multiplication of two power spectrum (real valued), the coherence function is real and has values between 0 (no linear relationship between the two signals) and 1 (perfect linear relationship between the two signals). The result is usually given in percentage.

In practice, each signal is decomposed in $I$ equally spaced samples centred on a post. Inter and auto spectra are then computed as the mean over I samples

$$
S_{x y}\left(f_{k}\right)=\frac{1}{I} \cdot \sum_{i=1}^{I} X\left(f_{k} ; i\right) \cdot Y\left(f_{k} ; i\right)^{*}
$$

with

$$
X\left(f_{k} ; i\right)=\sum_{n=0}^{N-1} x(n ; i) \cdot e^{-J \cdot \frac{2 \pi \cdot f_{k}}{N \cdot F_{E}}}
$$

where

- $X$ is the discrete Fourier transform of the time signal $x$,

- $F_{E}$ is the sample frequency,

- $f_{k}$ is the frequency of evaluation of the coherence function,

- $\quad \gamma_{\mathrm{x}, \mathrm{y}}{ }^{2}\left(f_{k}\right)$ is the coherence function (without units) between $x$ and $y$ at frequency $f_{k}$,

- $S_{x y}\left(f_{k}\right)$ is the Cross Power Spectrum between the signals $x$ and $y$ at frequency $f_{k}$,

- $S_{x x}\left(f_{k}\right)$ Power Spectrum of the signal $x$ at frequency $f_{k}$,

Since the model and test are random, one has $l$ simulation and $m$ measurements. The final coherence at a frequency is the average $l \times m$ coherences. The curve will be shown in black. The process is repeated for each measurement with respect to all others and the average curve is shown in red. It is assumed that simulation coherence with measurements cannot be higher than measurements with each other. To be able to compare with nominal results (i.e. with no irregularity), its coherence with measurements is shown as a green line.

To ease the comparison of various cases a scalar measure of coherence is introduced by computing the surface under the curve defined by $\gamma_{\mathrm{x}, \mathrm{y}}{ }^{2}\left(f_{k}\right)$ for frequencies between 0 and $20 \mathrm{~Hz}$. This scalare represents the percentage of coherence between the group of simulations and the group of measurements for this range of frequencies. 


\subsection{Sample results}

Simulations are performed with OSCAR for a nominal model containing 3600 elements and 3200 nodes, for a section containing 14 spans. Train speed is fixed at $320 \mathrm{~km} / \mathrm{h}$ with a simulation over $700 \mathrm{~m}$ (10 spans). Time consumption is about 2 minutes, which gives the possibility to make 3000 simulations for all irregularity cases in around 100 hours. The work is distributed over several computers.

\section{Comparison of simulations}

The most widely used criterion is $\sigma / F_{m}$. Its mean $\mathrm{M}_{3}$ must be as small as possible for a good collection. $M_{3}-M_{\text {nom }}$ gives the mean impact of irregularities. The range of variation defined by $\mathrm{Min}_{3}$ and $\mathrm{Max}_{3}$ gives additional information of the tendency. Associated values are given in Table 1. As a complement Figure 6 gives a histogram of $\sigma / F_{m}$.

Geometric irregularity has a strong impact on current collection quality. This impact can be strongly positive or negative as the values $\operatorname{Max}_{3}$ and $\operatorname{Min}_{3}$ show. The distribution is almost centered on the nominal value and the standard variation induced by this irregularity on $\sigma / F_{m}$ is $\pm 3.7 \%$ of the mean value $\left(S_{3} / M_{3}\right)$.

Wear irregularity is the second most influent irregularity at $320 \mathrm{~km} / \mathrm{h}$ according to Figure 6. But the way it is defined here only induces positive impact on current collection. The contact force is globally smoothed where wear is high, which is located on the area of high force. Consequently, standard deviation of contact force $\left(S_{2}\right)$ is reduced.

Aerodynamic irregularity has a very small impact on standard deviation of the contact force $\left(S_{2}\right)$. The main modification is induced on mean force $\left(S_{1}\right)$, which can be explained by the way the simulation is performed. The aerodynamic signal is indeed averaged to zero over the whole simulation, which is different from the period on which statistical values have been computed. The impact of aerodynamic irregularity can therefore be taken into account simply by varying the mean force with $\pm 13 \mathrm{~N}$ as seen previously, which leads to a standard variation on $\sigma / F_{m}$ of $\pm 9 \%$ of $M_{3}$.

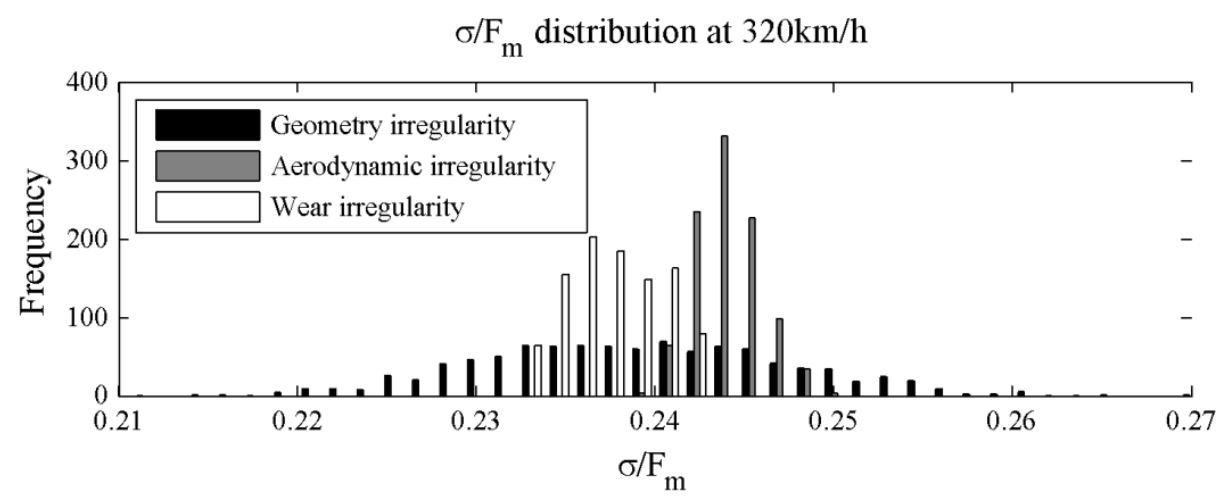

Figure 6. Distribution of the geometry (black), aerodynamic (grey) and wear (white) irregularities for 1000 simulations each

The second result, shown in Figure 7, is the spectrum of contact force differences for each irregularity. Span frequency and harmonics are given with vertical dotted lines. It appears that the impact of geometric irregularity is focused on span frequencies, which is consistent with the fact that the energy of contact force is higher at these frequencies. 
The same behaviour is observed with wear irregularity in a more ambiguous way. It is although not the case of aerodynamic irregularities. This observation confirms the previous conclusion about the lower impact of aerodynamic irregularity on contact force variation around its average.

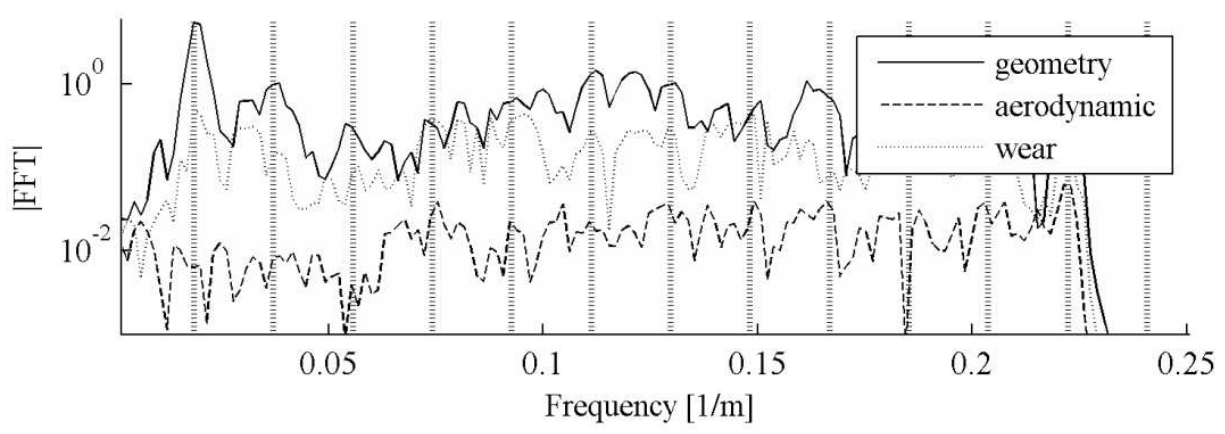

Figure 7. Mean of spectra of contact force differences for geometry (solid line), aerodynamic (dashed line) and wear (dotted line) irregularities, with span harmonic frequencies (vertical lines)

Table 1. Results of statistical values of sets of contact forces simulated

\begin{tabular}{|c|c|c|c|c|c|c|c|}
\hline & $\mathrm{M}_{\text {nom }}$ & $\mathrm{M}_{3}$ & $\mathrm{Min}_{3}$ & $\mathrm{Max}_{3}$ & $\mathrm{~S}_{3}$ & $\mathrm{~S}_{1}$ & $\mathrm{~S}_{2}$ \\
\hline \multirow{2}{*}{ Geometric irregularity } & \multirow{3}{*}{0.2427} & 0.2391 & 0.211 & 0.270 & 0.009 & 0.183 & 1.20 \\
\cline { 1 - 7 } Wear irregularity & 0.2377 & 0.233 & 0.242 & 0.003 & 0.01 & 0.34 \\
\cline { 1 - 6 } Aerodynamic irregularity & & 0.2441 & 0.240 & 0.250 & 0.002 & 0.628 & 0.181 \\
\hline
\end{tabular}

\section{Measurement-simulation comparison}

In order to compare model and test variations, the FBA and coherence criteria give visual support.

On the FBA graph in the left column of Figure 8, surfaces with transparency represent the range between maximum and minimum observed values for corresponding set of simulations (in dark grey) and measurements (in light grey). Nominal behaviour is shown in black dotted line. One can see the energy variation of the contact force at a specific frequency, namely, the range of variance at this frequency. Geometric irregularity represents far better the amplitude of variations observed in measurements than the two other which are nearly unnoticeable. For frequencies higher than $0.1 \mathrm{~m}^{-1}$, wear irregularity seems to be more representative than aerodynamic irregularity. The low level of FBA variability in the aerodynamic sensitivity analysis is coherent with the low level of spectrum differences in Figure 7.

On frequency coherence charts in the right column of Figure 8, frequency dependent spectrum linearity is assessed between the set of measurements and the set of simulations. Coherence between simulations and measurement can at best be equal to coherence between measurements themselves. Wear and aerodynamic irregularities clearly improve global coherence, which is represented by the grey area. This means that phase and frequency variations induced by these irregularities are representative of measured variations unlike what happens with geometry irregularity. 
Values of the scalar coherence criterion, given in Table 2, give a similar trend than the qualitative conclusion on frequency dependence. In particular, the mean coherence between geometry-irregularity simulations is quite low. One thus expects that geometry irregularity induces significant non-linearities into the pantograph-catenary system. Understanding why FBA and coherence criteria lead to different conclusions on the representativity of variability models seems an interesting direction for future work.

(a)

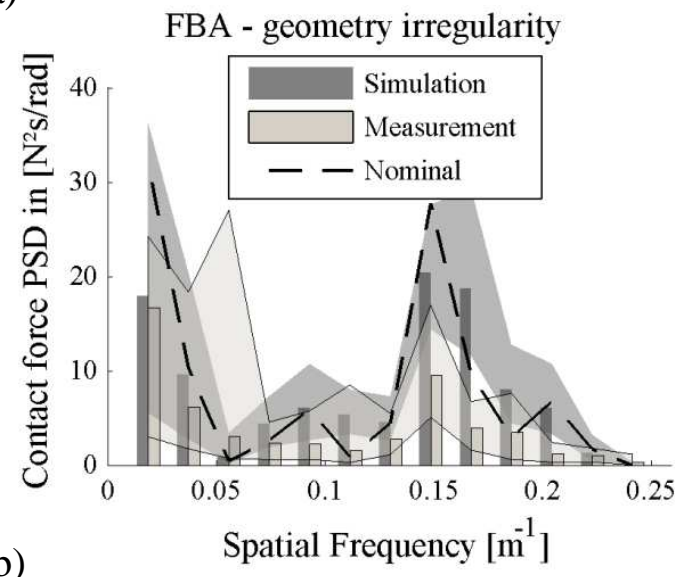

(b)

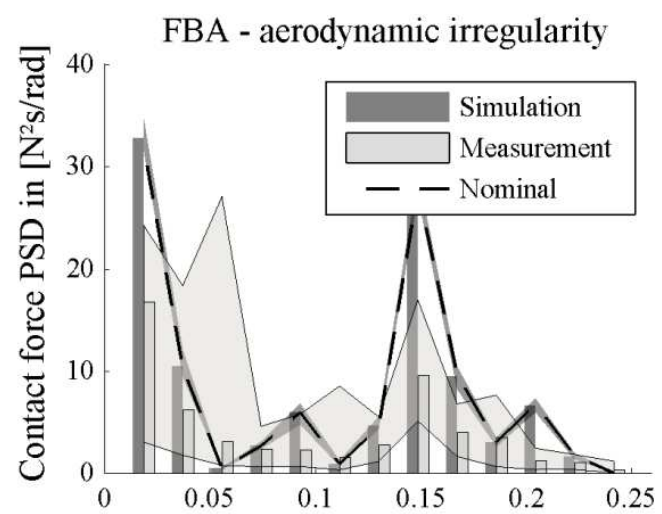

(c)

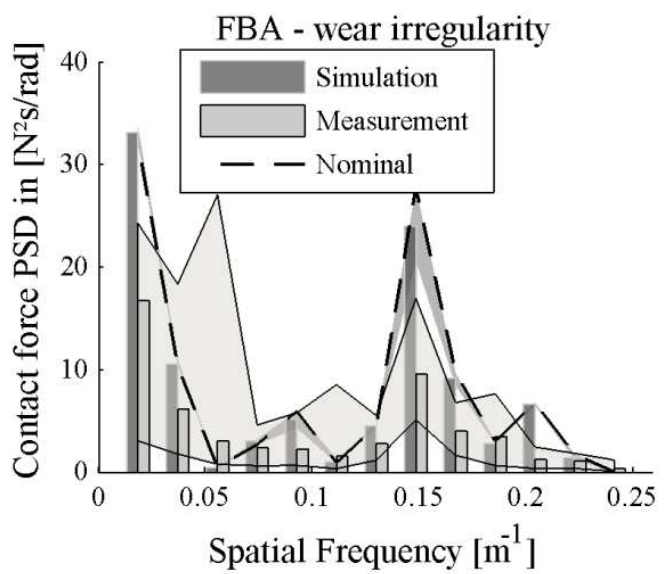

Frequency coherence - geometry irregularity

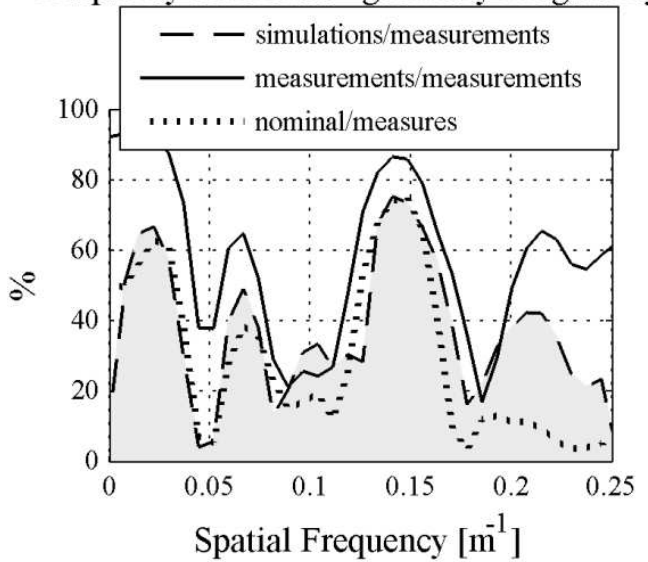

Frequency coherence aerodynamic irregularity

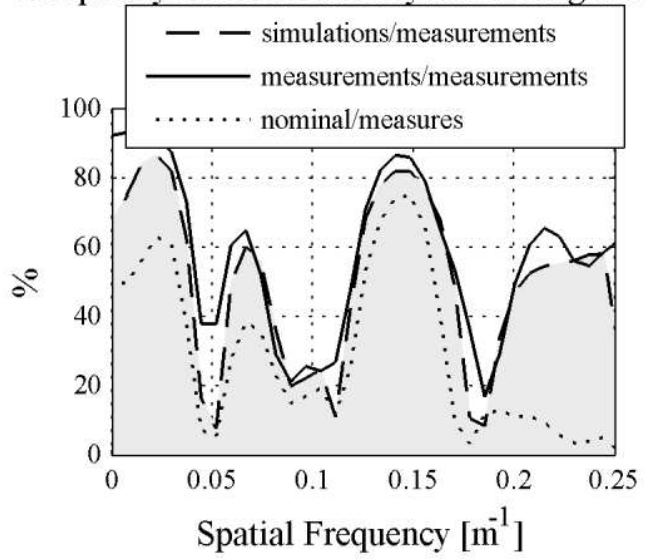

Frequency coherence - wear irregularity

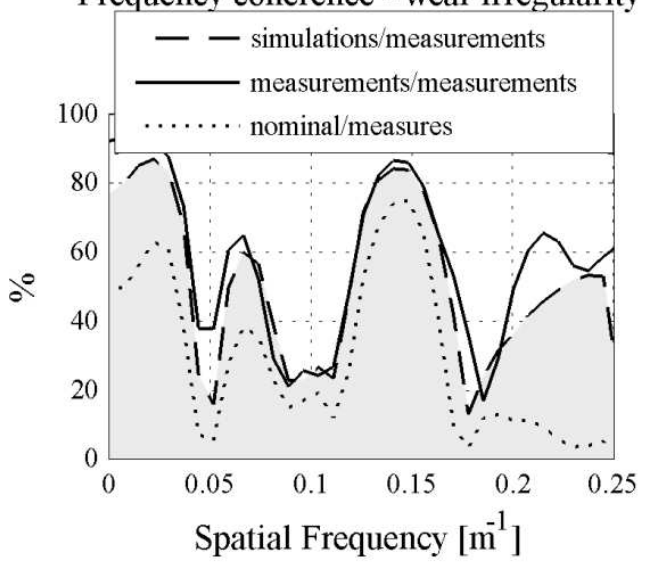

Figure 8. Frequency band analysis (left) and frequency coherence (right) of geometry (a), aerodynamic (b) and wear (c) irregularities. 
Table 2.Percentage of coherence for each type of irregularity

\begin{tabular}{|c|c|c|c|c|}
\hline $\begin{array}{c}\text { Mean Coherence between } \\
{[0-20] \mathrm{Hz}}\end{array}$ & $\begin{array}{c}\text { Simulations/ } \\
\text { Measurements }\end{array}$ & $\begin{array}{c}\text { Nominal/ } \\
\text { Measurements }\end{array}$ & $\begin{array}{c}\text { Measurements/ } \\
\text { Measurements }\end{array}$ & $\begin{array}{c}\text { Simulations/ } \\
\text { Simulations }\end{array}$ \\
\hline Geometric irregularity & $38.91 \%$ & & & $64.95 \%$ \\
\cline { 1 - 1 } Wear irregularity & $52.37 \%$ & $32.13 \%$ & $58.11 \%$ & $95.37 \%$ \\
\cline { 1 - 2 } Aerodynamic irregularity & $50.60 \%$ & & & $95.10 \%$ \\
\hline
\end{tabular}

\section{Example of use in virtual certification}

Virtual certification is a promising approach to use numerical simulations. The European project PantoTRAIN (see [9]) led to a full procedure to extend pantograph certification to different catenary systems. The recent certification of a new pantograph in France and Spain was an opportunity to lead a blind test in parallel to inline tests. This pantograph has the particularity to be insensitive to the airflow and has a twice lower bow mass. Wear is very low on the catenary used for the inline tests. Geometry irregularity is thus the main known source of variability.

The analysis is based on three sets of dynamic contact forces:

- Inline tests, which are dynamic forces obtained directly from an equipped pantograph on the train at four different speeds,

- Simulations with nominal geometry, which correspond to simulations made at the same speeds and mean forces as the inline tests with the nominal catenary defined in section 2.1

- Simulations with measured geometry, which correspond to simulations made at the same speeds and mean forces as the inline tests with the geometry measured under the catenary modelled

Figure 9 displays the simulation value of $\left(F_{m}-3 \sigma\right)$ with black triangles in comparison to the measured values in light grey triangles for the same values of mean forces as shown by the circles. The tests show a dispersion of mean force which generates dispersion on $\left(F_{m}-3 \sigma\right)$. This criterion is almost the same as $\sigma / F_{m}$, since it follows the same goal, but has to be over zero and consequently as high as possible. The curves $F_{m \text {,min }}$ and $F_{m \text {,max }}$ correspond to the minimal and maximal values of the mean contact forces authorized by the recent TSI.

Table 3. Deviation on $\sigma$ depending on the speed and presence of geometry irregularity shows three comparisons between dynamic inline tests, simulations with nominal geometry and simulations with measured geometry over the section used for the model. The difference on the prediction of $\sigma / F_{m}$ between tests and simulations is computed for the four speeds. At each speed, the value of $\sigma / F_{m}$ is averaged. The left column is obtained by comparing inline tests with the nominal catenary and the central one with the measured height of the catenary. The right one compares simulations obtained with measured and nominal geometries.

The difference between both nominal and measured geometries is only of $2 \%$ at $320 \mathrm{~km} / \mathrm{h}$. At every other speed, the difference between simulations is between $14 \%$ and 
$17 \%$, which means that either the speed or the mean force (or both) has an influence on the geometric irregularity impact on contact force.

Inline test are based on different sections and each of them has a geometry that differs from that used in simulations. In the central column, the value of $\sigma / F_{m}$ of inline tests however seems to be always lower than simulations. This implies that the representation of geometric irregularity used here includes cases that have significantly different impact from what is actually found in test. One thus includes too many geometry configurations within the way the geometry irregularity is defined.
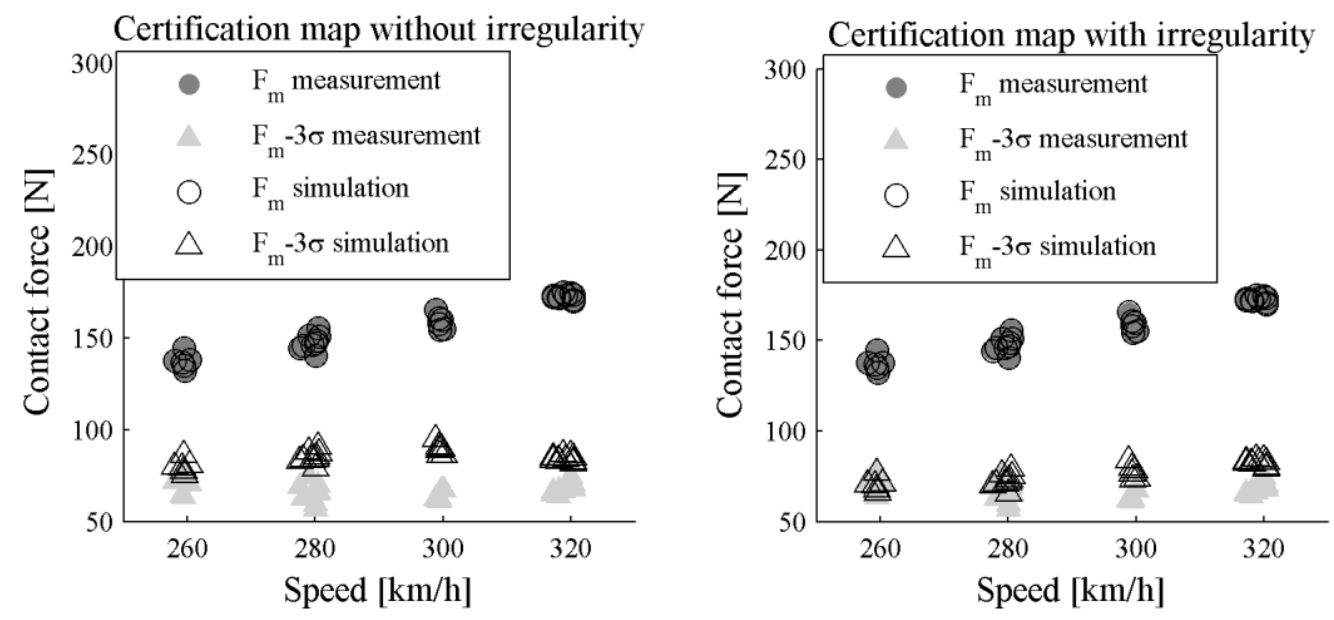

Figure 9. Comparison between inline tests and simulations with nominal geometry (a) and comparison between inline tests and simulations with measured geometry.

Table 3. Deviation on $\sigma$ depending on the speed and presence of geometry irregularity

\begin{tabular}{|c|c|c|c|}
\hline \multirow{2}{*}{ Speed $[\mathrm{km} / \mathrm{h}]$} & \multicolumn{3}{|c|}{ Relative deviations on $\sigma / F_{m}$} \\
\cline { 2 - 4 } & $\begin{array}{c}\text { Nominal geometry /Inline } \\
\text { tests }\end{array}$ & $\begin{array}{c}\text { Measured geometry } \\
\text { /Inline tests }\end{array}$ & $\begin{array}{c}\text { Measured geometry / } \\
\text { Nominal geometry }\end{array}$ \\
\hline 260 & $-15 \%$ & $-0.7 \%$ & $14 \%$ \\
\hline 280 & $-24 \%$ & $-9 \%$ & $17 \%$ \\
\hline 300 & $-26 \%$ & $-14 \%$ & $15 \%$ \\
\hline 320 & $-16 \%$ & $-14 \%$ & $2 \%$ \\
\hline
\end{tabular}

\section{$6 \quad$ Introduction of speed and mean force variations}

Since the impact of variable geometries was shown to depend on speed, one seeks to further characterize this dependence. In order to compare simulation results to those obtained for the virtual certification, one computes two sets of simulations at $300 \mathrm{~km} / \mathrm{h}$ and $320 \mathrm{~km} / \mathrm{h}$ with the mean force $F_{m, 300}$ obtained at $300 \mathrm{~km} / \mathrm{h}$ and the thousand geometries previously generated.

Figure 10(a) shows the distribution of mean force for variable geometries at three different design points. The mean force distribution show little impact from speed, 
or the mean force. For the average of $\sigma / F_{m}$ and $\sigma$, as show Figure 10(b) (c), speed has clearly a higher influence than mean force. It is difficult to draw more conclusions from this figure.

Figure 11 shows the histograms of $\sigma / F_{m}$ for two speeds and a correlation plot where each point is associated with a geometry and the resulting $\sigma / F_{m}$ at the two speeds. The correlation plot is elongated along the diagonal, which implies that there is a strong correlation for both variation of mean force and speed. One can observe a higher dependence between two different mean forces $F_{m}$ than between two different speeds. This qualitative observation can be quantified by the correlation defined as

$$
r_{1,2}=\frac{\operatorname{cov}\left[\left(\sigma / F_{m}\right)_{1},\left(\sigma / F_{m}\right)_{2}\right]}{\sigma\left[\left(\sigma / F_{m}\right)_{1}\right] \times \sigma\left[\left(\sigma / F_{m}\right)_{2}\right]}
$$

which gives $\mathrm{r}_{\mathrm{Fm}}=96,4 \%$ and $\mathrm{r}_{\text {Speed }}=88.9 \%$ where $\mathrm{r}_{\mathrm{Fm}}$ is the correlation between $\sigma / F_{m}$ of the sets $\left(320 \mathrm{~km} / \mathrm{h}, \mathrm{F}_{\mathrm{m}, 320}\right)$ and $\left(320 \mathrm{~km} / \mathrm{h}, \mathrm{F}_{\mathrm{m}, 300}\right)$ and $\mathrm{r}_{\text {Speed }}$ is the correlation between $\sigma / F_{m}$ of the sets $\left(300 \mathrm{~km} / \mathrm{h}, \mathrm{F}_{\mathrm{m}, 300}\right)$ and $\left(320 \mathrm{~km} / \mathrm{h}, \mathrm{F}_{\mathrm{m}, 300}\right)$. Speed thus has more influence than mean force when considering the impact of geometry on contact force.
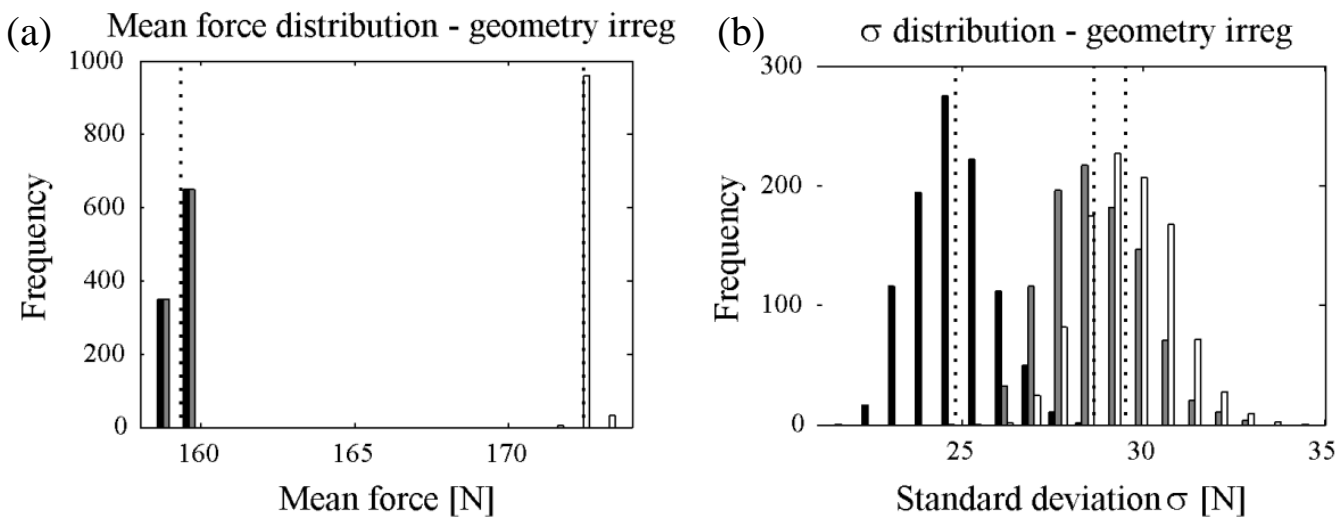

(c) $\sigma / \mathrm{F}_{\mathrm{m}}$ distribution - geometry irreg
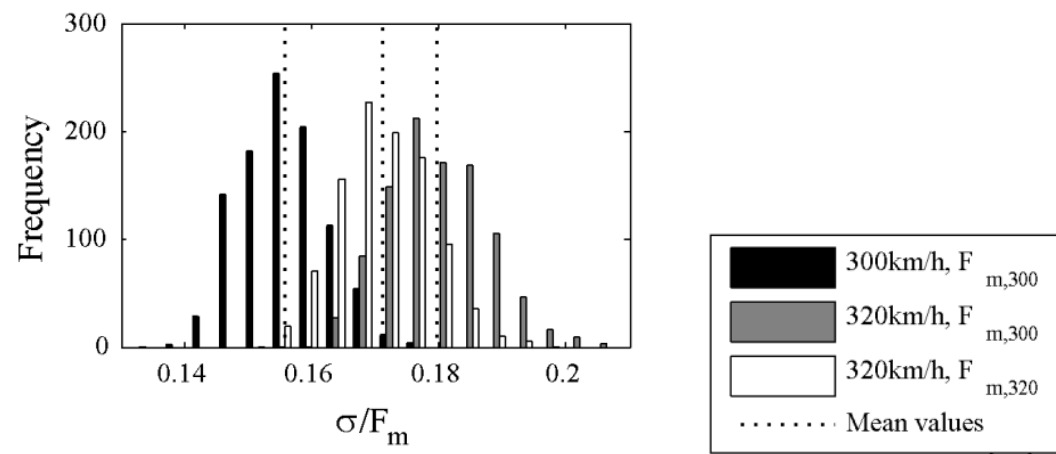

Figure 10. Mean force (a), standard deviation (b), $\sigma / F_{m}(\mathrm{c})$ distributions for one thousand geometric irregularities at three different design points (speed, mean forces): $300 \mathrm{~km} / \mathrm{h}$ and $F_{m, 300}$ (black), $320 \mathrm{~km} / \mathrm{h}$ and $F_{m, 300}$ (grey), $320 \mathrm{~km} / \mathrm{h}$ and $F_{m, 320}$ (white). 
(a)
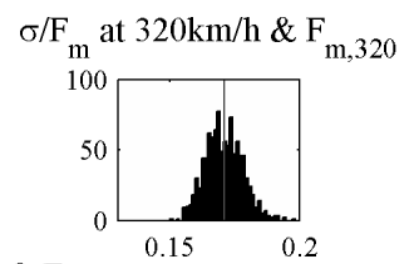

$\sigma / \mathrm{F}_{\mathrm{m}}$ at $320 \mathrm{~km} / \mathrm{h} \& \mathrm{~F}_{\mathrm{m}, 300}$

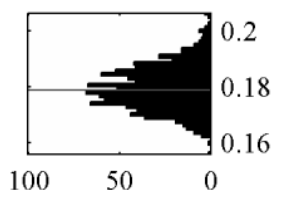

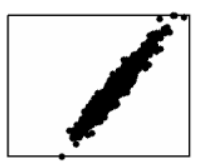

(b)
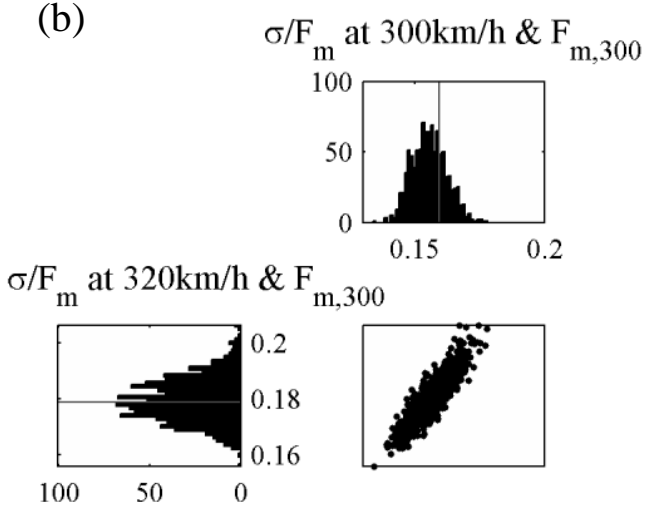

300

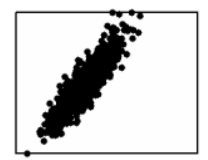

Figure 11. Dependence on (speed, mean force) of the criterion $\sigma / F_{m}$ for two groups of design points: $\left(320 \mathrm{~km} / \mathrm{h}, \mathrm{F}_{\mathrm{m}, 300}\right)$ against $\left(320 \mathrm{~km} / \mathrm{h}, \mathrm{F}_{\mathrm{m}, 320}\right)(\mathrm{a})$ and $\left(320 \mathrm{~km} / \mathrm{h}, \mathrm{F}_{\mathrm{m}, 300}\right)$ against $\left(300 \mathrm{~km} / \mathrm{h}, \mathrm{F}_{\mathrm{m} 300}\right)(\mathrm{b})$. The nominal values are indicated by the solid lines.

One now seeks to evaluate how representative the random geometry is of the measurement by comparing the results of virtual certification with those of this method. By getting in the same conditions of speed and force as those which led to the results of Table 3, one can define a range of variation of $\sigma / F_{m}$ at $\left(300 \mathrm{~km} / \mathrm{h}, F_{m, 300}\right)$, which can be deduced knowing the variation of $\sigma / F_{m}$ at $\left(320 \mathrm{~km} / \mathrm{h}, F_{m, 320}\right)$ from the nominal.

Figure 12. Dependence on (speed, mean force) of the criterion $\sigma / F_{m}$ between two design points, $\left(300 \mathrm{~km} / \mathrm{h}, \mathrm{F}_{\mathrm{m}, 300}\right)$ against $\left(320 \mathrm{~km} / \mathrm{h}, \mathrm{F}_{\mathrm{m}, 320}\right)$. shows the combined influence of speed and mean force. The nominal values of $\sigma / F_{m}$ for both design points are indicated in thin solid line. The intersection is thus the position of the nominal geometry. In order to locate the position of the geometry irregularity used for the Table 3 , one draws a vertical thick dotted line $2 \%$ higher than the nominal value for the design point $\left(320 \mathrm{~km} / \mathrm{h}, F_{m, 320}\right)$. One then qualitatively define the limits of values of $\sigma / F_{m}$ at $\left(300 \mathrm{~km} / \mathrm{h}, F_{m, 300}\right)$ taken around this line. These limits are indicated in horizontal thin dotted lines. The range of variation thus defined is around [-8\% 8\%] around the nominal value. The result of $15 \%$ obtained in virtual certification is clearly out of range. One concludes that the random generation of irregularity is not very representative of the measurements used.

One thus seeks to explain the origin of this gap. The last difference between simulations computed for virtual certification and these ones is the length of simulation; three catenary sections were used for the certification. Figure 13 shows the contact force at $\left(300 \mathrm{~km} / \mathrm{h}, F_{m, 300}\right)$ for measured and nominal geometries. Three stretches have been defined to compute the relative deviation between the $\sigma / F_{m}$ of both signals. 


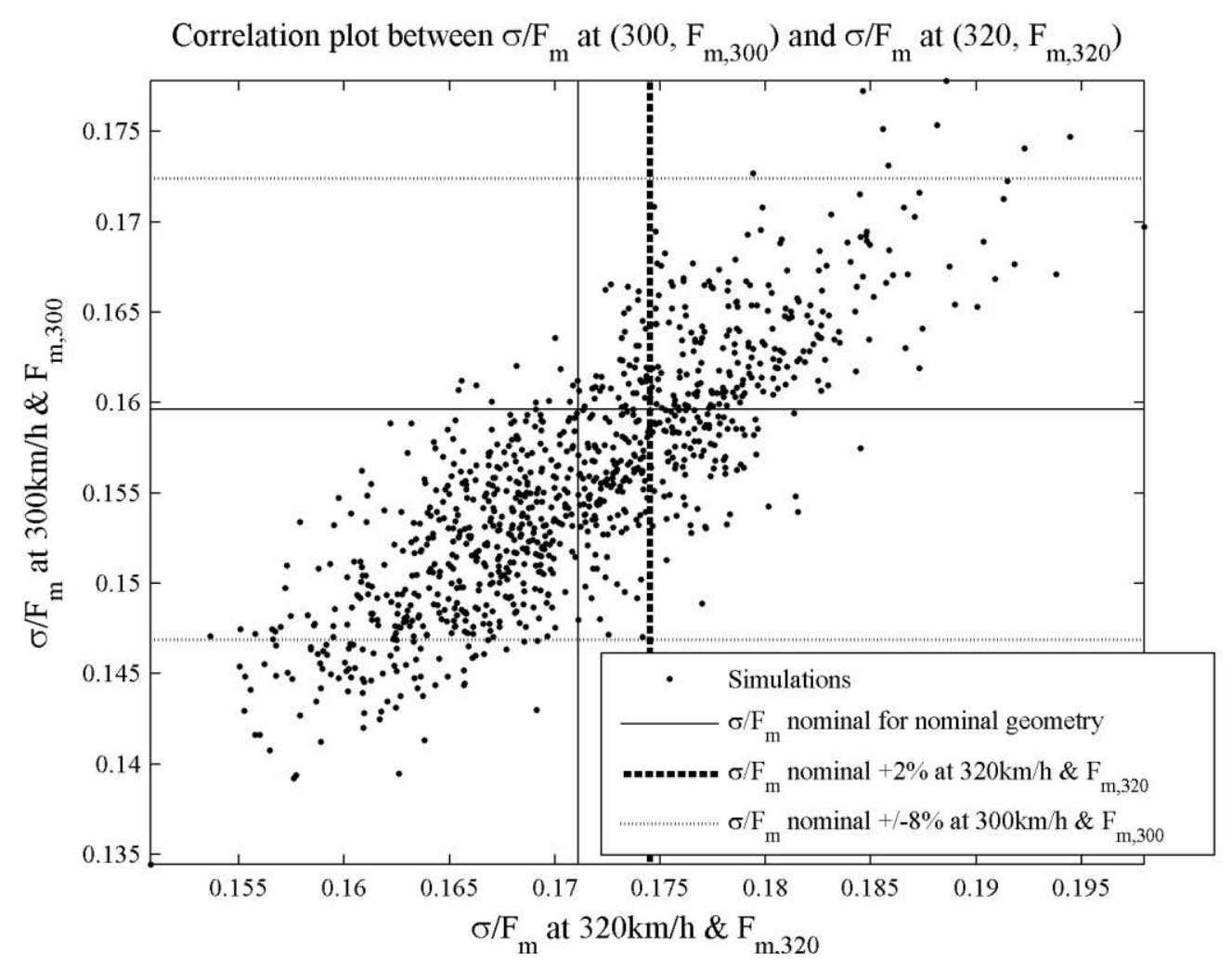

Figure 12. Dependence on (speed, mean force) of the criterion $\sigma / F_{m}$ between two design points, $\left(300 \mathrm{~km} / \mathrm{h}, \mathrm{F}_{\mathrm{m}, 300}\right)$ against $\left(320 \mathrm{~km} / \mathrm{h}, \mathrm{F}_{\mathrm{m}, 320}\right)$.

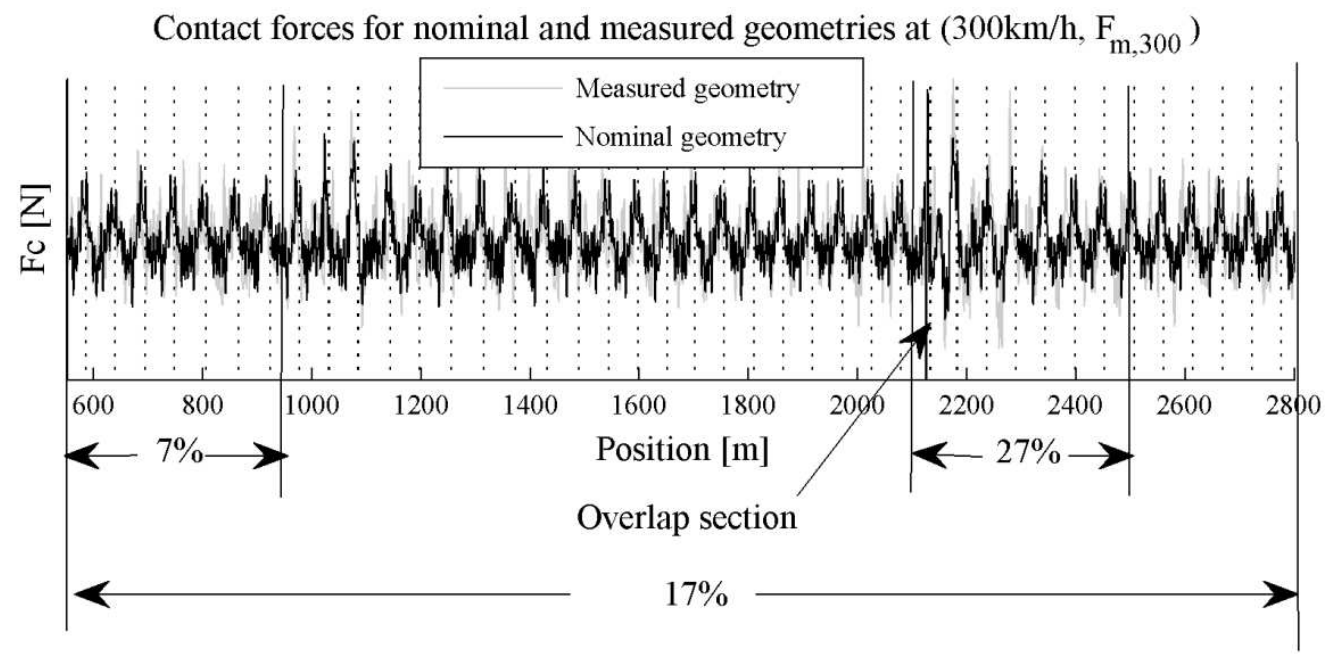

Figure 13. Contact forces along three catenary sections at $\left(300 \mathrm{~km} / \mathrm{h}, F_{m, 300}\right)$ for nominal (black) and measured (grey) geometries and relative deviations between $\sigma / F_{m}$ of measured and nominal geometries for three different zones.

The first stretch is the same as the one computed for the variability study with a length of $400 \mathrm{~m}$. The relative deviation of $7 \%$ is included in the interval defined previously in Figure 12. The random geometry generation method thus includes the measured case. The second stretch has the same length as the first one, namely $400 \mathrm{~m}$. It is located on and after an overlap section. The variation of $\sigma / F_{m}$ is $27 \%$. The last stretch is the whole simulation, on which the variation of $\sigma / F_{m}$ is $17 \%$, approximately the value given in 
Table $3(15 \%)$. One observes that the criterion $\sigma / F_{m}$ is not precise enough to compare several geometries and the location of variations can be discriminating, particularly for the overlap section.

To confirm this conclusion, that the location has a strong influence on current collection quality, and justify further developments, Figure 14 shows the variation of $\sigma / F_{m}$ computed over $400 \mathrm{~m}$ along the catenary. Higher values of local $\sigma / F_{m}$ are clearly located around overlap sections. This observation encourages developing more accurate criteria which take into account the location on a catenary section and avoid averaging critical areas.
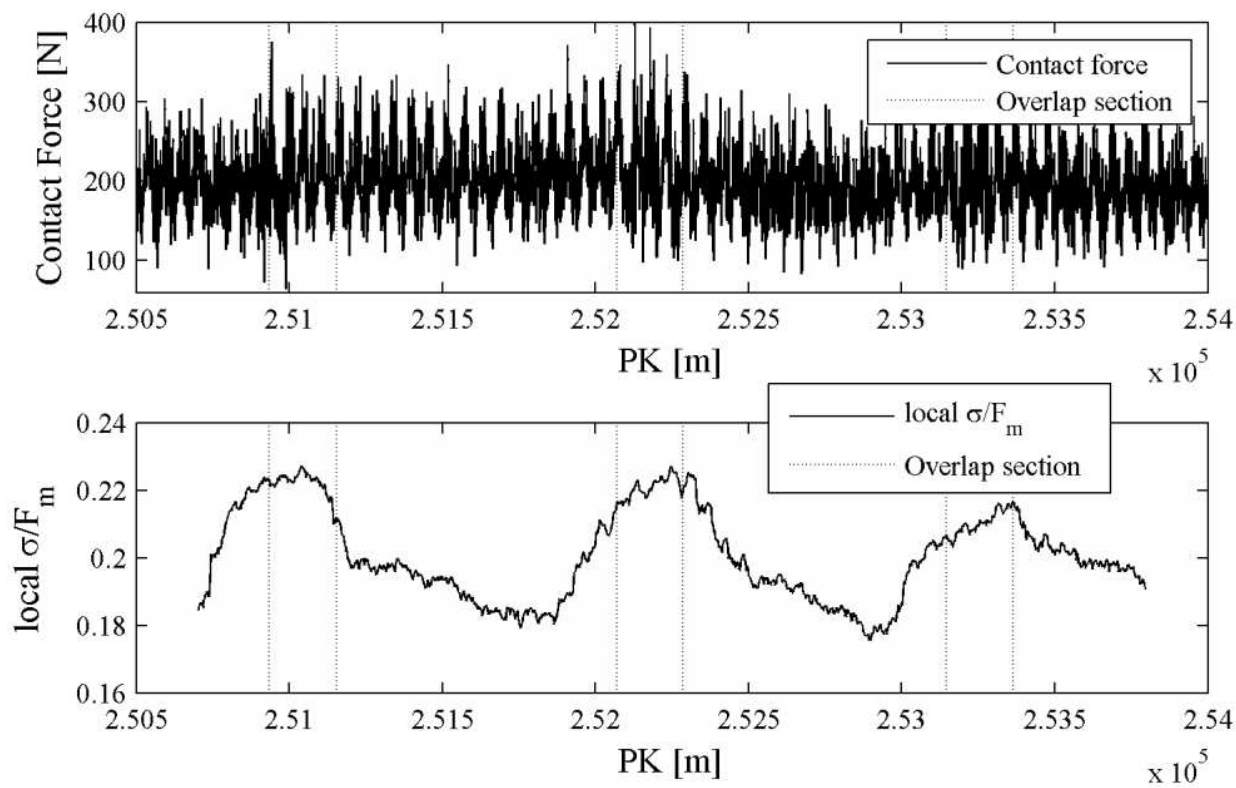

Figure 14. Measured contact forces at $320 \mathrm{~km} / \mathrm{h}$ (a) and local $\sigma / F_{m}$ defined from the contact force $200 \mathrm{~m}$ before and after the associated PK. Overlap sections are shown with vertical dotted lines.

\section{Conclusion}

The paper introduced variability in pantograph/catenary simulations due to three different types of irregularities and the following conclusions can be drawn.

Wear irregularity has a low impact on current collection quality, even in the entirely determinist case defined here, which amplifies this impact. This kind of irregularity improves significantly the frequency coherence. Simulations show a positive impact on current collection. Taking this kind of irregularity into account is thus not a priority.

Aerodynamic irregularity only impacts the mean contact force, without inducing any significant effect over time. As the energy variation of the load is low, this kind of irregularity nearly does not affect current collection quality if the average is removed. Taking a range for the averaged load is thus representative of the impact of aerodynamic irregularity.

Geometry irregularity induces variations of amplitude that are representative of measurements for low frequencies, but does not improve coherence with measurements. The variation of the normative criterion $\sigma / \mathrm{F}_{\mathrm{m}}$ indicates that this kind of irregularity has a 
high impact on current collection, which can be good or bad. As this irregularity has the most impact on current collection, further studies on appropriate representation are clearly needed.

The last section first showed that speed has more influence than mean force on the impact of the geometric irregularity. It then appeared that the proposed random geometries might include non-representative cases, so that further work on geometry characterization is needed. Finally, current criteria used to define the current collection quality were shown to vary depending on location.

The relatively simple examples of this paper demonstrated the importance of introducing variability in pantograph catenary models. Quantification of uncertainty, introduction of other variable parameters, further sensitivity studies, more careful statistical interpretation of tests and redefinition of criteria are clear perspectives for future work.

\section{Acknowledgements}

This paper describes work undertaken by SNCF Research and Innovation Department with the precious support of SDTools and Vibratec companies. The Authors would like to thank particularly Jerôme Antoni for his contribution on the signal-processing field.

\section{References}

[1] S. Bruni et al., The pantograph-catenary interaction benchmark, IAVSD n. 23 (2013)

[2] C. Gomez, R. Saa et al., A model to obtain optimal designs of railway overhead knuckle junction using simulation, Simulation Modelling Practice and Theory 26 (2012), pp. 16-31

[3] J. Pombo, J. Ambrosio, Influence of pantograph suspension characteristics on the contact quality with the catenary for high speed trains, Computers and Structures 110 - 111 (2012), pp. 32-42

[4] J.-W. Kim et al., State sensitivity analysis of the pantograph system for a highspeed rail vehicle considering span length and static uplift force, Journal of sound and vibration, 303 (2007) pp. 405-427

[5] M. Aboshi, M. Tsunemoto, Installation Guidelines for Shinkansen High Speed Overhead Contact Lines, QR of RTRI, Vol. 52, No. 4, Nov. 2011

[6] E. Balmès, J.-P. Bianchi, J.-P. Massat, OSCAR 1.0 user's guide, SDTools/SNCF internal report, 2011

[7] S. Bruni, G. Bucca, A. Collina, Pantograph-catenary dynamic interaction in the medium-high frequency range, IAVSD n.18 (2004), Vol. 41, pp. 697-706.

[8] J.-P. Massat, C. Laurent, Simulation tools for virtual homologation of pantographs, International Conference on Railway Technology, 2012.J. Antoni, Cyclostationarity by examples, Mechanical systems and signal processing, Vol. 23, Issue 4, May 2009.

[9] UNIFE, PantoTRAIN WP3 deliverable 3.2, internal report, May 2012 p. 89 - 93 and p. $93-100$. 